\title{
Additions to the List of Newton Noctuidae.
}

The following names are to be added to those given in the list on 1). 34-39 of the present volume of Psxche; the abbreviations are the same as in that list.

Diphtera fallax. R. l. Jl.

Apatela Radcliffei. R.; raised. Jn.

Lrv. Prunus, Sp.

Agrotis badicollis. R. l. Au.

" fennica. Several s. Sp.

" albipennis. 'Two s. 1. Sp.

" incivis. R.; three s. Sp.

" trabalis. Cocoon found un-

der bark of Pinus strobus in April.

Imago appeared in June.

Hadena impulsa. R. l. Jl.

" apamiformis. R. I. Jl. Au.

" vultuosa. C. l. Au.

“ leucoscelis. R. s. Au.

Dryobota stigmata. R. s. Sp.

Laphygma trugiperda. C. s. Sp.

Prodenia flavimedlia. R. s. Sp.

" lineatella. R. l. Jl. $[P$. ornithogalli is to be stricken from the previous list.]

Gortyna limpida. R. I. Sp.

Arzama densa. R. l. Au.

Nonagria sp. One l. Au.

Doryodes acutaria. R. l. Au.

Platysenta atriciliata. R. I. Jn. Jl.

Parasticlitis minuscula. R. l. s. Au. Sp.
Glaea viatica. S. Oct. 19.

" inulta. Several s. Sp.

" deleta. (See below.)

Scopelosoma Graefiana. Several s. Sp. Oct. Nov.

Lillophane seniiusta. R. s. Sp. 28,

Oct. 18.

" Georgii. One s. Sp.

" laticinerea. C. s. Sp.

Oct.

“ tepida. R. s. Sp.

“ querquera. R. s. Sp.

“ Baileyi. (Grote, Can.

Entom., ix, 86). Several s. Sp. Oct. Nov.

“ viridipallens ' (Grote,

Can. Entom., ix, 215).

R. s. Sp. Oct.

Plusia formosa. One 1. Jl.

" verruca. One s. Au.

Galgula hepara. One s. Nov.

Catocala neogrma. R. s. q. Au.

" piatrix. R. q. s. Au. Sp.

Homoptera Woodii (Grote, Can.

Entom., ix, 88-89).

R. I. Jl.

Spargoloma 6-punctata. R. l. Jl.

The new species mentioned in the above list is described as follows, by Mr. Grote :-

Glaea deleta n. sp. $\sigma^{\star}$. Belongs, with G. tremula, to the section which I have called Epiglaea, in which the thorax has a sharp scale-ridge. Resembles $G$. viatica at first sight, but belongs with $G$. pastillicans to a different section of the genus. Expanse, $46 \mathrm{~mm}$. Of the same color as G. viatica, but smaller, and with the transverse posterior line punctate, and the subterminal also broken into spots. Stigmata pale ringed, well sized, concolorous; reniform stained at base. The markings are faint. Hind wings fuscous above; with discal spot and line beneath. Antennæ white at base. Abdomen with ochery anal hairs. (A.R. Grote.)

Rare, at sugar, in September. Several (poor) specimens were taken at sugar in October.

Noctuae have been abundant here this fall. Besides the additional species of Lithophane mentioned above, I have taken all those given in my former list. The larvæ of Lithophane disposita and $L$. Bethunei were found last June at the roots of apple and willow trees.

R. Thaxter.

Nos. 39-40 were issued Jan. 12, 1878. 

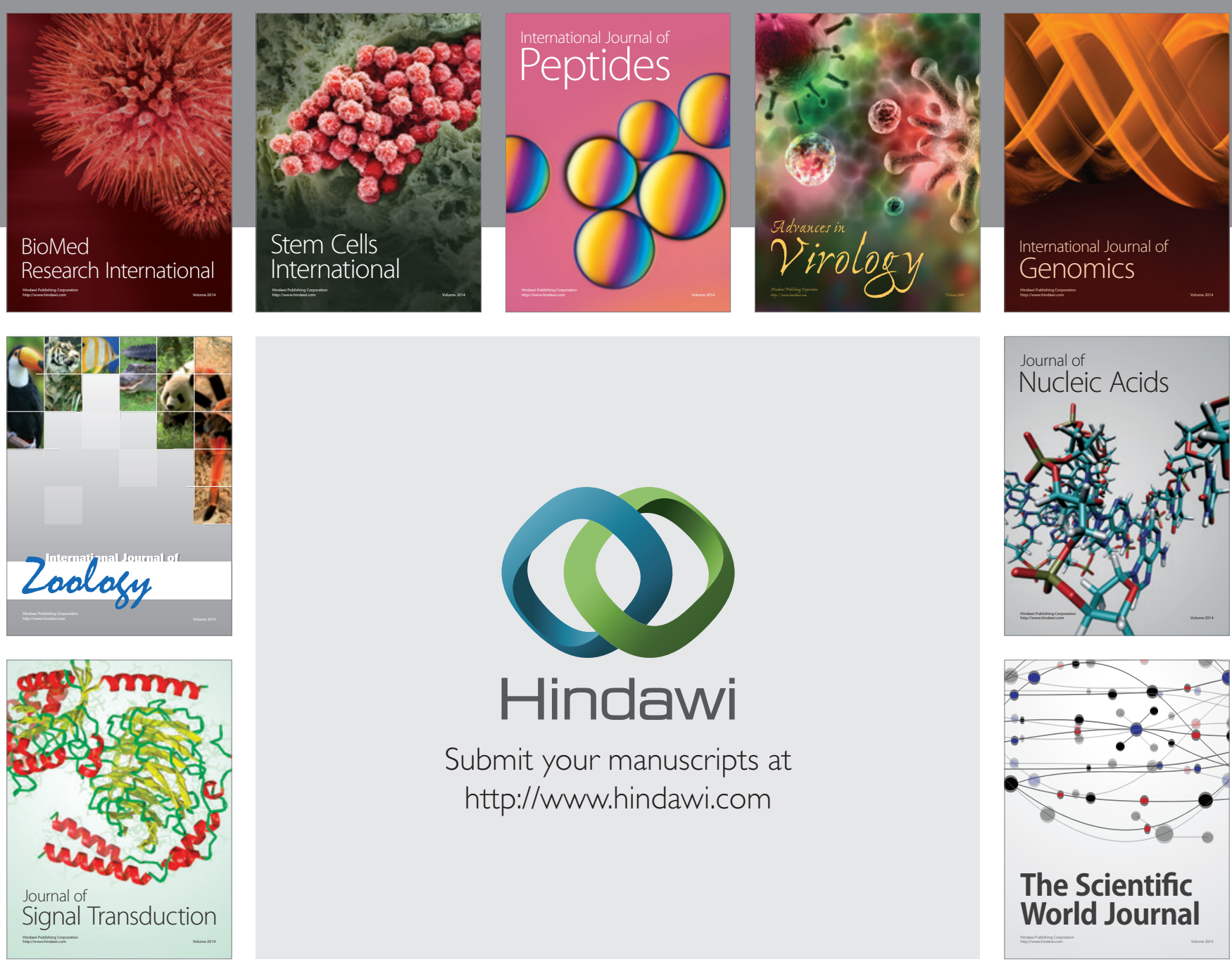

Submit your manuscripts at

http://www.hindawi.com
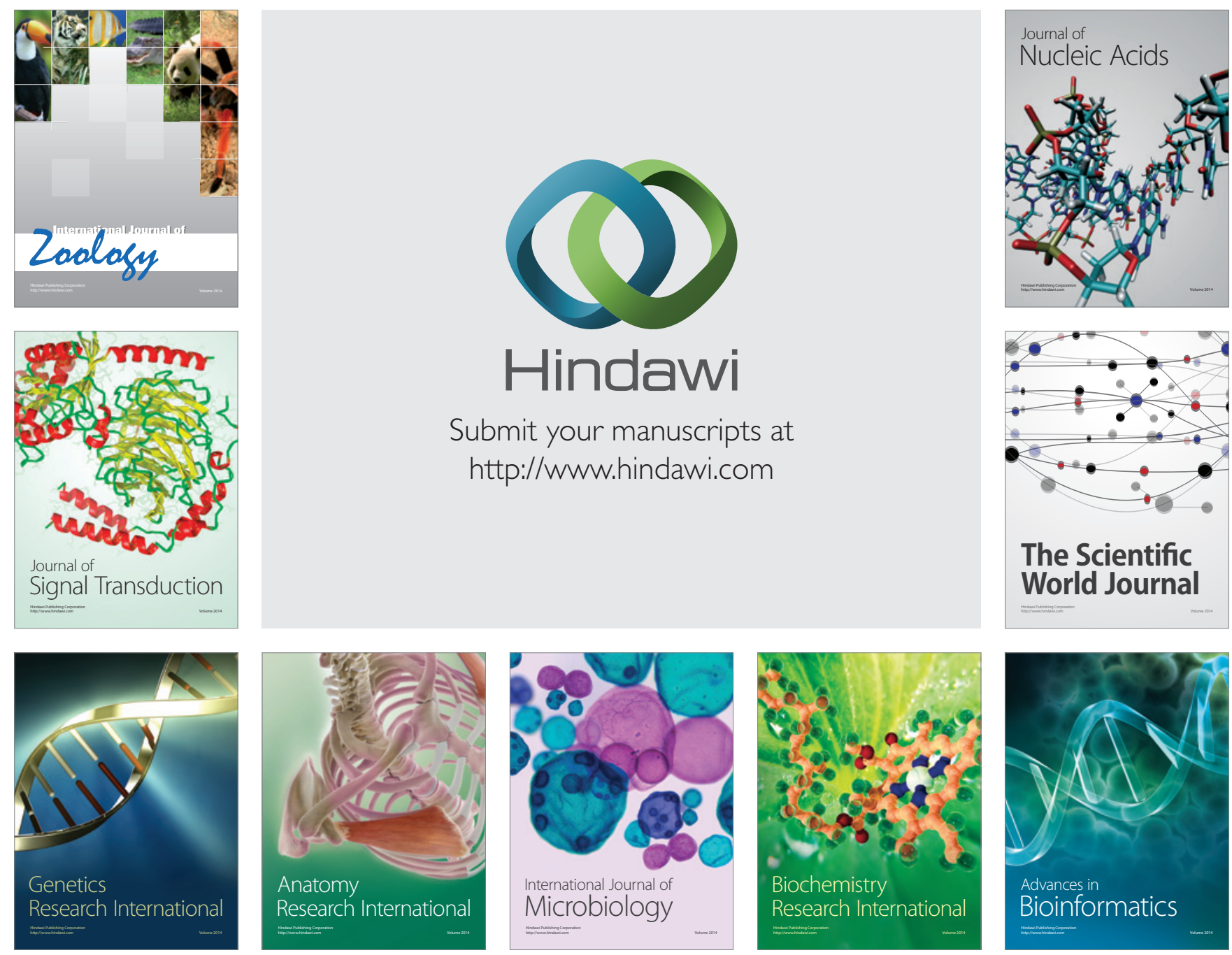

The Scientific World Journal
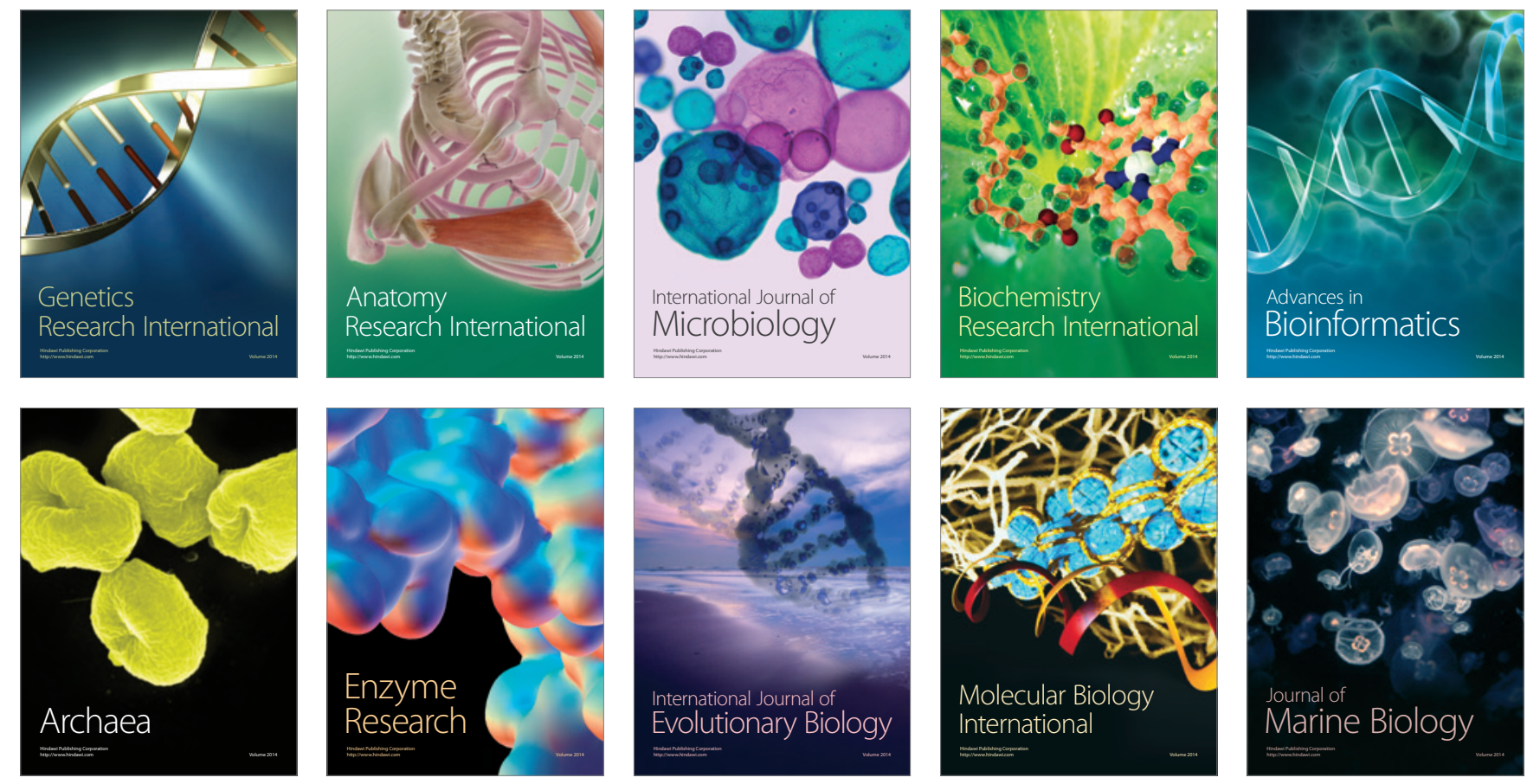